\section{La representación de la diversidad afectivo-sexual en la literatura infantil y juvenil de América Latina}

\author{
GUILLERMO SOLER QUILES \\ Universidad de Alicante
}

\author{
Guillermo Soler \\ Profesor asociado en la Facultat \\ d'Educació, departamento de In- \\ novación y Formación Didáctica, \\ Universitat d'Alacant, desde 2013 \\ Profesor de enseñanza secundaria, \\ área de lengua castellana y litera- \\ tura, Conselleria d'Educació de la \\ Comunitat Valenciana, desde 2004. \\ Máster en Investigación Educativa \\ por la Universitat d'Alacant, 2013. \\ Licenciado en filología hispáni- \\ ca por la Universitat de València, \\ 2001.
}

\title{
RESUMEN
}

En el siguiente trabajo se pretende analizar la literatura infantil y juvenil publicada en América Latina que muestra la diversidad afectivo-sexual. Se estudian los distintos modelos de familia formados por dos padres o dos madres, así como las historias que son protagonizadas por personajes no heterosexuales, y se comparan con publicaciones similares en otros lugares. Se puede concluir que las familias homoparentales son retratadas de un modo muy similar en todas las partes del mundo, sin embargo, en cuanto a la representación de lesbianas, gais, bisexuales y transgéneros, América Latina destaca por mostrar una mayor variedad de personajes, opciones, gustos y tendencias.

Palabras clave: Literatura infantil y juvenil, diversidad afectivo-sexual, LGTB, LGTBQ, LGBT.

\section{ABSTRACT}

The aim of this paper is to analyse children's literature published in Latin America showing sexual diversity. It intends to analyse the different types of families, formed either by two fathers or two mothers, as well as stories featuring non heterosexual characters and compare them to similar literature published elsewhere. It can be concluded that homo families are portrayed in a very similar way in all parts of the world, however, in the representation of lesbian, gay, bisexual and transgender, Latin America stands out to show a greater variety of characters, options, tastes and trends.

Keywords: Children's literature, Sexual affective diversity, LGTB, LGTBQ, LGBT.

En el nuevo contexto político y social ${ }^{1}$ que pretende igualar y equiparar en derechos a la comunidad formada por lesbianas, gais, transgéneros ${ }^{2}$ y bisexuales (LGTB), ha surgido un nuevo campo temático en la literatura dirigida a los jóvenes e infantes con personajes y contenidos que muestran esta diversidad afectivo-sexual. A partir de los álbumes ilustrados, los cuentos y las novelas juveniles publicadas en América Latina que serán analizadas en este trabajo, más allá de un planteamiento por géneros discursivos o geográficos, se ha realizado una clasificación temática de estas producciones: por un lado, aquellos textos que reflejan familias homoparentales, formadas por dos madres o dos padres; por otro, aquellos que muestran en sus historias personajes que se alejan de la heterosexualidad. La literatura infantil cuenta con una doble transmisión de valores, los literarios junto a los sociales (Llorens 2015), y aunque puede que algunos de los títulos comentados en este análisis no destaquen por su calidad literaria, sin embargo, suponen la
1

En la actualidad, en 2015, veinte países en el mundo han regulado las leyes que permiten casarse a parejas del mismo sexo, así como la adopción de niños y niñas; todo un avance en derechos para la comunidad LGTB que empezó Holanda en 2001 y que continuaron países latinoamericanos como Uruguay, Argentina - México. La ley no se desarrolla ajena a la sociedad que rige, viene acompañada de movimientos políticos, reivindicaciones sociales, así como de una literatura que ayuda a construir reflejar o retratar esta sociedad.

2

Transgénero, entendido como un término que engloba las diferentes identidades de género: transexual, travesti, drag, andrógino, genderqueer o género fluido.

\footnotetext{
La representación de la diversidad afectivo-sexual en la literatura infantil y juvenil de América Latina
}

GUILLERMO SOLER QUILES 
integración en la lectura de los más pequeños los valores que permiten luchar contra los prejuicios generados en torno a la diversidad afectivo-social.

El cuestionamiento del discurso heteronormativo se hace patente desde las primeras manifestaciones literarias: la Biblia, en el Deuteronomio, prohíbe los cambios de vestimenta entre géneros, lo que implica su existencia previa; en la mitología griega, Aquiles se viste de mujer para intentar librarse de la guerra; Ovidio, en su Metamorfosis relata cómo algunas mujeres eligieron vivir como hombres: Ifis, Ceneo... (Ruiz Elvira 1995). En la novela caballeresca la dama que decide luchar como guerrero adquiere la categoría de tópico literario con el virgo bellatrix. En la cuentística popular aparecen cambios de sexo gracias a la aparición de seres mágicos que dotan de falo a aquellos personajes que no nacieron biológicamente varones. El folclorista Aurelio M. Espinosa (2009) recoge en Cuenca el cuento de «El oricuerno», en el que una muchacha se hace pasar por varón tras dar muerte a los asesinos de su novio; la hija de su jefe se enamora y se casan. En la noche de bodas, la verdad es revelada y la novia engañada decide aceptar la situación sin problemas; analizado desde un prisma actual esto supone bien la conformidad de un matrimonio lésbico, bien la aceptación de un matrimonio formado por un transgénero y una mujer heterosexual. Sin embargo, los vecinos empiezan a sospechar del protagonista con el paso de los años, pues la pareja no tiene hijos. Tras pasar varias pruebas en las que demuestra ser varón, el muchacho transgénero debe pasar la más difícil: bañarse desnudo en el agua. Antes de esta exposición aparece el oricuerno, un ser fantástico que la somete a una reasignación de género mágica. En su análisis, Espinosa compara cuatro versiones del mismo cuento, una de ellas mexicana; en esta tienen lugar ciertas variantes sobre el cambio de sexo, pues este se produce con la intervención de un toro que, tras ser toreado por el joven transgénero, propicia un intercambio: su vagina se transforma en pene y el toro se convierte en vaca, una versión que se acerca a las tradiciones orientales del cambio de sexo.

Las diferentes versiones del oricuerno, con sus variantes, ponen de manifiesto un doble planteamiento: la diversidad afectivo-sexual aparece retratada desde las primeras mani- festaciones artísticas, por un lado; por otro, el elemento mágico aparece con la intención de restaurar la heterosexualidad obligatoria (Butler, 2007), de restituir ese binarismo masculino femenino, es decir, de solucionar ese problema que tienen los otros. Esa mayoría masculina, machista, patriarcal se va a imponer en nombre de la religión, primero, del discurso científico después, hasta tal punto que la diversidad afectivo-sexual se silenciará, se perseguirá y se castigará hasta la primera mitad del siglo XX. Las primeras manifestaciones literarias dirigidas a los infantes no aparecen hasta finales del este siglo, aunque empiezan a proliferar con la entrada al nuevo milenio. El primer álbum ilustrado que muestra una familia formada por dos hombres se publica en Dinamarca el año 1981, Mette bor hos Morten og Erik, traducido al inglés dos años después como Jenny lives with Eric and Thomas (1983), y estuvo marcado por la misma polémica que acompañará a muchas de estas publicaciones. Para Clyde \& Lobban, (2001) se trata del primer álbum ilustrado que resiste la opresión y celebra la diferencia, mostrando una sociedad abierta y libre. Unos años más tarde, se publica en Suecia la primera novela juvenil protagonizada por un adolescente gay, Duktig pojke (1986), cuya traducción literal sería buen chico, aunque se publica al español como Jim en el espejo.

En el ámbito anglosajón, títulos como Ferdinando el toro (1936), que prefiere oler flores a pelear, William's Doll (1972), que muestra el deseo de un niño por conseguir una muñeca que su padre le niega, u Oliver Button es una nena (1979), porque quiere bailar en lugar de jugar a fútbol, ofrecen una galería de personajes que se salen de la conducta establecida, que cuestionan los límites del género y, por tanto, suponen un claro precedente de la literatura infantil de temática LGTB, siguiendo el análisis de Jamie Campbell Naidóo en Rainbow Family Collections (2012). El primer libro estadounidense de madres lesbianas, Lots of Mommies (1983), todavía representa a la familia con ciertas sutilezas. En 1989, se publica el primer libro en el que aparece un personaje con sida; sin hacer referencia explícita a su homosexualidad, esta queda reflejada a través de las ilustraciones: Losing Uncle Tim. Este mismo año, Lesléa Newman autoedita (pues ninguna editorial se atreve a publicarlo) Heather has Tro Mommies, donde muestra infantil y juvenil de América Latina

GUILLERMO SOLER QUILES 
claramente a dos lesbianas preparando la fiesta de cumpleaños de su hija. En la trama se incluye una explicación sobre la inseminación artificial que provocará tal polémica que su autora, en el décimo aniversario de la publicación, decidió eliminar esa parte. Hoy en día el álbum es considerado un clásico y su autora un referente internacional especializada en los libros infantiles de temática LGTB.

Con el nuevo milenio se empieza a producir cierto grado de normalización, se empiezan a mostrar con naturalidad las familias con dos madres. En este sentido, Naidóo (2012) destaca la editorial española Topka que en 2006 es la primera en publicar libros de cartón (para niños y niñas más pequeños) en los que Manu tiene dos mamás, sin más, que le enseñan a poner la mesa, a irse a la cama o le advierten del peligro. Las editoriales más pequeñas, como ocurre en el ámbito anglosajón, se encargan de publicar este tipo de obras. Destacan la catalana Bellaterra, la vizcaína A Foritori y la salmantina Lóguez. En los grandes sellos editoriales prácticamente es inexistente la diversidad afectivo-sexual. Teresa Colomer (2004) pone en relieve la presencia de cuentos de novias, que no de novios, unas historias de lesbianismo que aumentan a un mayor ritmo en el álbum ilustrado que en las novelas juveniles. Alrededor de veintinueve obras de ficción, entre 1986 y 2005, se publicaron en España con esta temática. Cencerrado y Cedeira ${ }^{3}$ (2006) destacan cómo en diez años las producciones LGTB se han ampliado: álbumes, relatos, novelas... La oferta ha aumentado considerablemente, y sin embargo el mercado no ha crecido en la misma proporción: la presencia de obras que luchan contra la misoginia o el racismo aumenta a un ritmo que se ralentiza cuando se trata de diversidad afectivo-sexual. En cuanto al álbum ilustrado, estos dos autores señalan que se produce un boom editorial entre 2003 y 2005, con dos líneas argumentales muy evidentes: una, más realista, cuyo marco es la familia diversa, donde predomina la pareja lésbica, que será mejor aceptada socialmente, con hijas adoptadas o biológicas; en su mayoría se trata de discursos en primera persona en los que la voz del niño o niña adoptado narra su vida cotidiana, basándose en relaciones afectivas donde la comunicación reina en una familia socialmente aceptada. Por norma, el miedo a la diferencia define la presencia del otro, del antagonista, bien sea un niño, sus padres o todo un pueblo. Otra vertiente, más fantástica, muestra cuentos de príncipes y princesas que acaban en bodas reales del mismo sexo, un intento de ruptura de estereotipos, ya utilizados anteriormente para romper con la misoginia. Unas líneas argumentales que se pueden hacer extensivas tanto a los cuentos cortos como a la novela juvenil en las producciones latinoamericanas en las que se mantiene este tratamiento con respecto al realismo en los casos de familias homoparentales; sin embargo, no se produce en la misma proporción la vertiente fantástica.

En primer lugar, en México encontramos la editorial Patlatonalli en cuya colección Todas las Familias Somos Sagradas han sido publicados cuatro álbumes ilustrados que retratan diferentes modelos de familia. Tengo una tía que no es monjita, (2004) de Melissa Cardona y Margarita Sada, narra la historia en primera persona a través de los ojos de una niña cuya tía ni tiene esposo, ni parece querer tenerlo. Un buen día la sobrina observa a su tía besándose con otra mujer, al preguntar extrañada por qué lo hace la tía le revela que se trata de su novia. Una respuesta simple y afectiva que no problematiza ni oculta ninguna situación, por lo que la sobrina entiende la situación de un modo sencillo. Cabe destacar que el personaje de la tía, con quien comparte nombre la protagonista (aunque el lector lo desconoce), se construye como una mujer que reivindica la cultura latinoamericana frente al consumismo capitalista americano, un planteamiento político a través de un uso culinario, que le aporta profundidad y entidad al personaje lésbico en este caso.

En los siguientes tres títulos de la editorial mexicana son mostrados tres modelos de familia diferentes, todos ellos protagonizados por una hija con madres que se alejan del modelo heteronormativo. En el primer caso, Las En 2006, la revista Educación y Biblioteca dedica un dossier monográfico a la diversidad sexual en su número 156. Ofrece un panorama general de los estudios sobre temática LGTB en España, tanto la presencia de material en las bibliotecas y en las escuelas de la diversidad sexual y afectiva, como su presencia en las obras literarias $y$ libros de texto. 


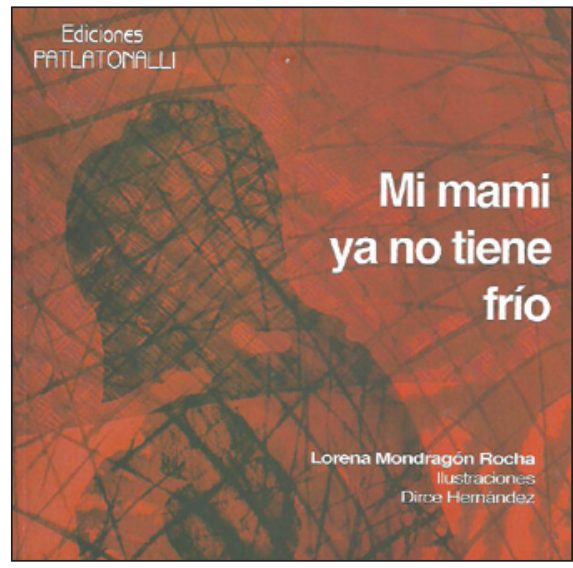

Mi mami ya no tiene frío, de Lorena Mondragón Rocha y Dirce Hernández. tres Sofías (2008), de Juan Rodríguez Matus y Anna Cooke, la acción se sitúa en Oaxaca, en una comunidad indígena, en la que la pequeña Sofía cuenta cómo su madre vive más feliz y llena de alegría con su nueva pareja Sofía Alvarado, a pesar de las presiones sociales. El siguiente álbum trata de una de adopción internacional: Xía y las mil sirenas (2009), de Tatiana de la Tierra y Anna Cooke, narra la llegada de una niña de origen asiático al seno de una familia con dos mamás, una pareja interracial, y un hermano mayor. Las mil sirenas que acompañan a Xía desde su origen suponen una metáfora de su mundo anterior, que decide compartir con su nueva familia al descubrir que forman parte de ella y no del exterior. Finalmente, en Mi mami ya no tiene frío (2012), de Lorena Mondragón Rocha y Dirce Hernández, igual que en el relato anterior una niña narra la historia de amor entre su madre, que vive con frío rodeada de libros, y una titiritera; una relación que al principio no resulta del agrado de la protagonista, hasta que comprende que su madre ha dejado de tener frío.

En su análisis de la literatura infantil y juvenil de temática LGTB Naidóo (2012) defiende que en los relatos de familias homoparentales las dos madres aparecen con mayor frecuencia, pero en su análisis denuncia que apenas aparecen recreadas parejas interraciales o culturas diversas en los álbumes infantiles. Una deficiencia que la editorial mexicana se encarga de subsanar, mostrando mujeres no heterosexuales de diferentes orígenes, procedencias o etnias. Una característica que comparten los textos mexicanos con las dos novelas juveniles que escribió la cubana Mildre Hernández: Es raro ser niña (2011) y su pseudo-prolongación Una niña estadísticamente feliz (2012). Ambas historias presentan a Cuasi como protagonista, una niña cubana mestiza, hija de una negra llamada Alma Blanco y de un rubio llamado Gregorio. Los padres están separados y la madre tiene una nueva pareja: Vida. Cuasi, una niña muy inteligente y despierta, se orina en la cama, motivo por el cual visita al psicólogo, quien justifica esta acción por los posibles conflictos de casa ya que sus padres biológicos no se llevan bien. Ambos libros cuentan con un abundante uso de metáforas y dobles sentidos, y de hecho Cuasi le explica a una compañera en qué consiste el doble sentido, mostrando una reflexión metaliteraria, constante en las dos novelas, que aportan calidad literaria al discurso de Mildre. Uno de los capítulos, titulado «el Armario», explica cómo hay gente que vive dentro de ellos: la primera novia de su madre, Elisa, a la que casaron con un marinero al que ve tres veces al año y el papá homófobo de su amigo Juan Carlos. Estas dos novelas cortas no pretenden falsear la realidad, no se trata de álbumes para infantes que puedan presentar finales edulcorados; son novelas aptas para leer a partir de los diez o doce años, en las que Cuasi se enfrenta a las discusiones de sus padres biológicos, así como retrata varios conflictos causados tanto por el machismo como por la homofobia social y escolar. Sin embargo, para la joven protagonista las relaciones lésbicas de su madre no suponen ningún conflicto ni problema, no forman parte del eje central de la novela. Este es un aspecto fundamental en la literatura infantil y juvenil que muestra temas o personajes LGTB, pues de acuerdo con Larralde: «es necesario que los personajes gais, lesbianas, transexuales, transgénero, interesex y las familias homoparentales estén, pero no necesariamente constituyan el foco de la narración. Que constituyan un elemento más dentro de la historia, una realidad más» (97).

Mostrar la cotidianeidad y la realidad de los diferentes modelos de familias parece una constante. En esta dirección se dirigen las publicaciones de la editorial argentina Librería de Mujeres Editoras. María Victoria Pereyra Rozas y Fernando Belisario en Mi vestido de lunares (2010) plantearon una situación anecdótica: una niña se ha propuesto encontrar una mariposa perdida en su casa, y para conseguirlo cuenta con la ayuda de sus dos madres: mamá Malena y mamá Sara. Sin más explicaciones ni porqués, sin la necesidad de explicar el origen de la familia, sin la necesidad de detallar cómo se ha formado esta familia... Fruto de la misma autoría se publica Se pegaron los fideos (2010): al papá Martín le toca cocina pero se le pegan los fideos, cosa que a sus hijas Valeria y Julieta les hace mucha gracia; por suerte llega papá Eduardo y explica la receta. Situación cotidiana que muestra 
con naturalidad el día a día de una familia formada por dos progenitores varones. De acuerdo con Larralde en esta obra no se produce ningún conflicto, prevalece la intención de representar una vida perfecta, sin problemas, rompiendo cualquier principio de verosimilitud al retratar estos temas sanamente como propone la editorial. Las ilustraciones muestran modelos que se alejan de cualquier representación local o multicultural, retratan rostros o ropas estándares, de cualquier lugar del mundo.

El polémico título chileno Nicolás tiene dos papás (2014) de Leslie Nicholls y Ramón Gómez (y Roberto Armijo como ilustrador), parece intentar mostrar un mundo ideal, sin conflictos, en el que vive Nicolás con sus dos padres. Sin embargo, carece de una mínima anécdota, simplemente pretende mostrar a una familia homoparental en su día a día. No contiene nada más que la presentación de los personajes: los dos padres, la madre y los compañeros del colegio, privando a la historia de cualquier aspecto literario. Antes de empezar la historia se puede leer: «todas las familias merecen respeto, protección e igualdad de derechos», editado por el Movimiento de Liberación Homosexual; se trata de un material didáctico para trabajar la diversidad afectivosexual con los más pequeños, subvencionado por el gobierno y disponible en la red. Si no se cuenta con el apoyo gubernamental, otro modo de publicar es la autoedición. De este modo vio la luz la historia de los dos canguros que querían ser padres: En busca del atesorado bebé canguro. Un cuento de paternidad gay (2011), de Camen Martínez Jover y Rosemary Martínez, muestra la llegada de un nuevo canguro a través de una donante de óvulos y un vientre subrogado.

La editorial Bajo el Arcoíris lleva desde 2011 publicando en la red una serie de cuentos de temática LGTB para descargar de manera gratuita. La argentina Sofía Olguín, editora y autora de este sello, señala en una entrevista que los títulos que publican «debían naturalizar la homosexualidad de la misma forma que los cuentos y las películas de Disney naturalizan la heterosexualidad» (Larralde 126). En su esfuerzo por retratar la diversidad afectivosexual se han convertido en la editorial que más ampliamente la muestra, con autores de diferentes latitudes latinoamericanas que publican cuentos, en verso o prosa, acompaña- dos de algunas ilustraciones un tanto naif. Tres de los títulos publicados por esta editorial versan sobre familias homoparentales: La familia de Martín (2011), de Nimphie Knox (pseudónimo de Sofía Olguín) y Lita Gómez, Mi conejo Mirlo (2012), de Nimphie Knox y Silfos (ilustraciones), y Rosa y Julieta mamás (2012), de Daniel Oropeza y Silfos. En el primero, un gato es recogido por una pareja gay formada por dos perros los cuales, a su vez, viven con un matrimonio formado por dos mujeres. En el siguiente, la hija de una pareja formada por dos hombres; uno de ellos decide regalarle un conejo como mascota, el otro padre amenaza con cocinarlo aunque finalmente se lo quedan. Rosa y Julieta mamás se ambienta en ciudad Barbie, un lugar en el que viven dos muñequitas Barbie con su hija pequeña la muñequita Carrie. Esta publicación resulta de especial interés por su carácter metaliterario: la pequeña se pregunta por qué razón en las historias que lee nunca aparecen dos mamás o dos papás, a lo que mamá Julieta le responde con otro cuento: este narra la historia de amor de las dos mamás, los problemas a los que se enfrentaron por culpa de la homofobia de algunas personas y, finalmente, la llegada de su amada hija. La pequeña Carrie se reconoce en el relato narrado y entiende al final del mismo que si no hay historias «ella, podría crearlas y escribirlas, así todos podían conocer que, en algún lugar del mundo (Barbie o humano), podría haber un niño con dos papás o dos mamás».

Retomando la clasificación de Cencerrado y Cedeira (2006) en lo que se refiere a las familias homoparentales las obras latinoamericanas convergen con el resto; sin embargo, en cuanto al segundo bloque temático, aquel en el que predominan príncipes gais y princesas
La representación de la diversidad afectivo-sexual en la literatura infantil y juvenil de América Latina GUILLERMO SOLER QUILES 


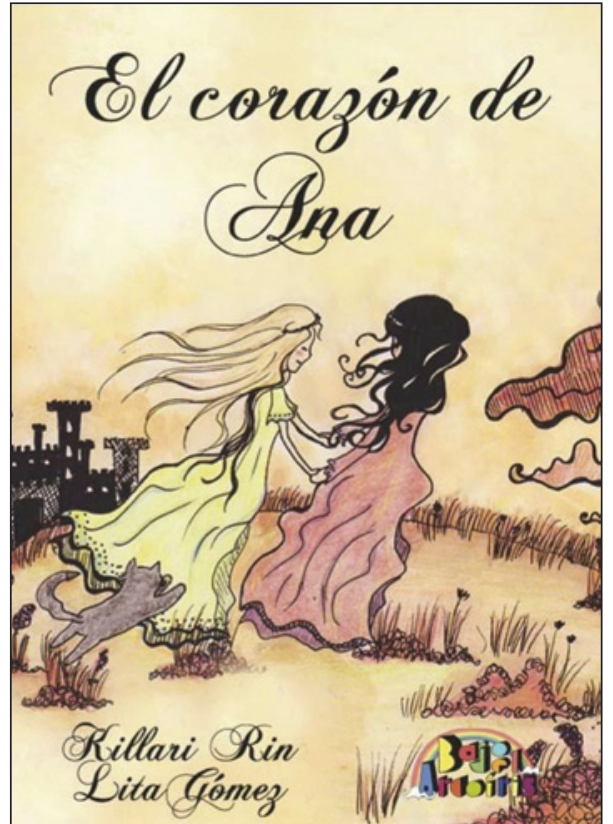

El corazón de Ana, de Killari Rin y Lita Gómez. lesbianas, no se corresponde del mismo modo, pues junto a este tipo de protagonistas de corte fantástico con hadas y duendes, aparecen otros personajes recreados siguiendo unas directrices más realistas. La editorial Bajo el Arcoíris cuenta con varias historias monárquicas: la primera de las publicaciones de este sello editorial fue Javier y el príncipe del mar (2010), de Nimphie Knox y Lita Gómez. En ella se narra la historia de amor entre dos jóvenes. Javier vive solo con su madre en una casa junto al mar, un día de pesca atrapa un pez parlante llamado Milo que resulta ser el príncipe del mar. Cuando este recupera su forma humana le descubre dos secretos: que Javier es príncipe del mar vecino, por un lado; por el otro, que Milo está enamorado y que desea casarse con él. La cubierta muestra a los dos protagonistas de espaldas, las siguientes ilustraciones sirven de apoyo visual a la narración. Cabe destacar y celebrar la última ilustración de todas porque se muestra a la pareja dándose un beso, algo muy poco frecuente en este tipo de cuentos. Las manifestaciones afectivas en las ilustraciones suelen estar relegadas al espacio heterosexual, incluso en estos álbumes que pretenden retratar la diversidad afectivo-sexual. Si se analiza en profundidad Tres con Tango (2005), de Peter Parnell, Justin Richardson y Henry Cole, el álbum que narra la adopción de un pingüino por parte de dos machos de su misma especie, apenas muestra manifestaciones de afecto entre ellos, parece que se besan en una especie de abrazo, mientras que hasta diecinueve ilustraciones muestran parejas heterosexuales en conductas románticas. La madre de Javier y Milo muestran un parecido extraordinario, prácticamente iguales, cosa que se explica porque entre ellos hay cierto grado de consanguinidad, característico de las relaciones entre la alta nobleza. Este parecido también invita a pensar en clave psicoanalítica, pues el joven Javier resuelve su Edipo reemplazando a su madre por un joven varón igual a ella. Milo presenta un as- pecto andrógino que se enfatiza con el uso de una corona que sujeta a modo de diadema su larga melena rubia; un nuevo acierto en este álbum que se aleja de estandarizar - heterosexualizar - a los protagonistas. Tres títulos más de tema monárquico son publicados en esta editorial argentina: El príncipe Flint (2011), de Hendelie y Lita Gómez, narra las aventura de un príncipe que decide abandonar su reino porque se meten con él, y lejos de allí conocerá al rey Pucklebee, quien le enseña que la belleza está más allá del aspecto físico; finalmente, vuelven al reino del Cajón y se casan. En El corazón de Ana (2012) de Killari Rin y Lita Gómez la princesa más joven del castillo se enamora del retrato de otra joven que resulta ser un hada atrapada por encantamiento. Cuando el hada se libera decide quedarse con Ana, prometerse y vivir su historia de amor en el mundo de los humanos. La magia de una sonrisa (2012) de Verónika Bohorquez y María Lemus narra la llegada de un mago llamado Sana a un castillo donde vivía un príncipe que no podía reír. Gracias a su magia, Sana consigue devolver la alegría al príncipe, así como conquistar su corazón.

No solo aparecen príncipes gais y princesas lesbianas. El sujeto transgénero como miembro de la realeza mantiene su presencia en cuentos infantiles, pero también cuentos cortos o novelas juveniles, lo que convierte al mercado latinoamericano como el más proclive a retratar las diversas identidades sexuales. Naidóo (2012) denuncia que se trata del colectivo más olvidado, señalando como únicos títulos publicados en Estados Unidos 10,000 Dresses (2008), de Marcus Ewert y Rex Ray, así como Gender Now Coloring Book: a learning Adventure for Children and Adults (2010), de Maya Christina González, que introduce por primera vez en un álbum infantil a los dos espíritus, transgénero nativos de las culturas indígenas americanas considerados seres casi divinos; además, el álbum incluye intersexuales y transgéneros alrededor de todo el mundo. En este sentido, de nuevo la editorial Bajo del Arcoíris ofrece dos álbumes con príncipes que devienen en princesas: Bron y el dragón (2011), de Nimphie Knox, en verso, y, en prosa, ¿Te gustaría ser mi Sol? (2012), de Sofía Olguín (esta vez publicado con su nombre) y Lita Gómez. Ambas historias aparecen precediinfantil y juvenil de América Latina

GUILLERMO SOLER QUILES 
das de una introducción sobre la reivindicación del colectivo transgénero y recuerdan la todavía necesaria lucha contra la transfobia. En el primer título el príncipe Bron ama al dragón Absalón, el cual ha sido rechazado por la princesa Julieta; el protagonista decide tomarse una poción, cambiar de género y conquistar a su amado. Cuando el príncipe se transforma su amigo dragón se convierte en su pareja y, finalmente, se casan. El otro cuento termina también en boda: la de Sebas y Sol, los cuales se enamoran cuando apenas tienen catorce él y doce ella. Sebas acompaña a Sol durante todo su proceso de cambio de género. Si en la primera historia Bron cambia totalmente su cuerpo gracias a una poción mágica, Sol decide no someterse a la operación de reasignación de género, evidenciando que no es necesaria para considerarse a sí misma una mujer. De este modo, con ambas historias se ponen de manifiesto las diferentes maneras de construir las identidades transgénero.

Fruto de unos talleres de creación literaria y diversidad afectivo-sexual nace Camila Caimán (2012), de Melina Montaño y María Celina Josens. Es una fábula de animales en la que un Caimán macho decide ponerse una flor rosa en la cabeza y comportarse como si fuera una hembra; en principio su familia la acepta, sin embargo cuando sufre la transfobia de sus vecinos, su familia deja de apoyarla. Camila decide huir de su pantano hasta que vuelve para avisar a sus familiares y vecinos que van a ser atacados; gracias a esta acción Camila será aceptada por los demás. No solamente se ha realizado una versión en títeres de esta historia, sino que fue declarado de interés cultural por el municipio de General Pueyrredón y pasó a ser distribuido como material pedagógico en las escuelas de Mar del Plata. Larralde (2014) recoge junto a este título dos más de temática transgénero: el álbum ilustrado titulado Yo nena, yo princesa. Luana la niña que eligió su nombre (2015), en el que Gabriela Mansilla escribe la historia de su hija, la primera niña transgénero en cambiar su nombre y su género legalmente en Argentina. Para Yellati (2015) se trata de «el relato del amor incondicional de una madre y de cómo se vio llevada a hacer de la supuesta posición sexuada de su hijo el ejercicio de un derecho». Si la historia de Camila está narrada en tercera persona por un narrador omnisciente y la de Luana

es contada por su madre, en la siguiente novela la voz narrativa, a modo de diario, la maneja Victoria, protagonista transgénero del relato. En Para Nina un diario sobre la identidad sexual (2012), de Enrique Torralba y Javier Malipca, se muestra la realidad de una joven que una vez se llamó Eduardo, sus preocupaciones, sus relaciones familiares, sus dudas, sus deseos, etc.

Heliópolis, el blus del hada azul (2012), del argentino Galileo Campanella, se presenta como una novela juvenil y como un cuento de hadas para adultos al mismo tiempo. En la contracubierta se puede leer además una pregunta retórica que permite situar al lector dentro de la temática sobre la identidad de género: ¿Sabías que el Hada Azul nació siendo un chico?, en referencia al hada que transformó en humano a Pinocho, una historia que aparece publicada primero en Internet y cuya lectura va acompañadas de códigos QR que amplían su lectura más allá del papel. Ambientada en un entorno mágico donde conviven personajes de los cuentos populares con otros nuevos, Azul es un joven que se pasa hasta los veintiún años ahorrando para poder huir de casa y convertirse en hada, una transformación que conlleva el cambio de género. En sus peripecias conocerá a dos

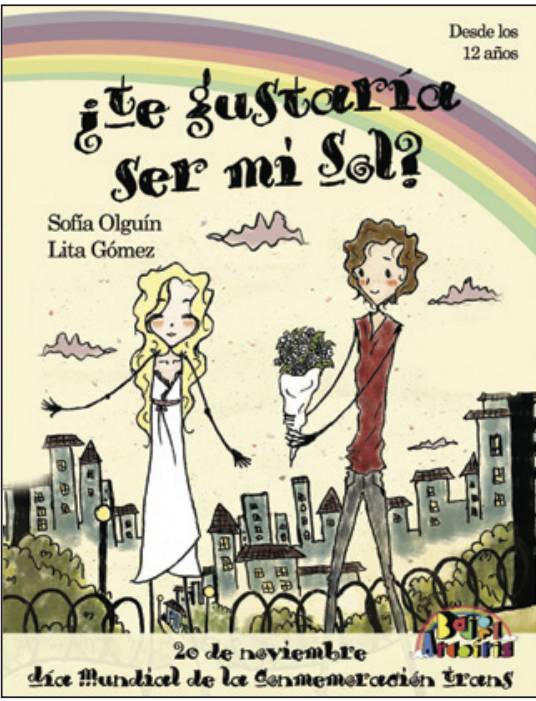

¿Te gustaría ser mi Sole, de Sofía Olguín.

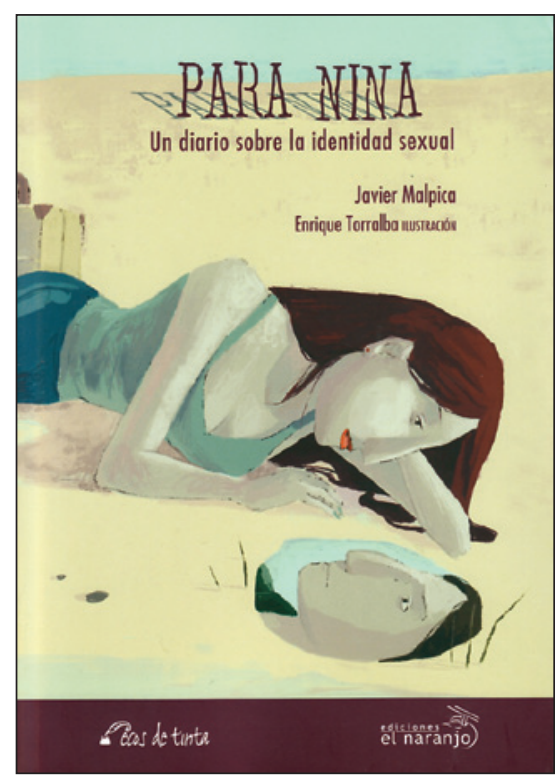

Para Nina un diario sobre la identidad sexual, de Enrique Torralba y Javier Malipca. hadas, que se dedican al mundo del espectáculo, que la ayudarán a realizar su transición a hada. Para esta transformación necesitará un vestido de fantasía, unas alas y acudir al doctor Unicornio, especialista en «Reasignación de especies. Órganos vestigiales y apéndices metafísicos. Extremidades supernumerarias»; un unicornio que recuerda al ser mitológico de la tradición española, el oricuerno, que conseguía cambiar el género con ayuda de su cuerno. Por fin Azul consigue reunir todo lo necesario para poder convertirse en hada, pero un giro rocambolesco de la historia obliga al unicornio a lanzar a través de su cuerno un rayo que si bien transforma a las tres hadas, también hace que desaparezcan, y mueran. De

La representación de la diversidad afectivo-sexual en la literatura infantil y juvenil de América Latina GUILLERMO SOLER QUILES 
tal modo que la historia de cómo el hada Azul de Pinocho nació varón no se sustenta, dado que al final desaparece antes de poder dar vida a la marioneta construida por Gepeto. No solamente esto: a la otra protagonista del relato, Rosa, la hermana secreta de Azul, joven heterosexual que no quiere cambiar de género, al ser tocada también por el rayo del Unicornio le empiezan a crecer unas pequeñas alas en su espalda. Lo que presupone que las hadas transgénero no tienen cabida en el mundo de la fantasía, el cual parece perpetuar el modelo heteronormativo del orden no mágico.

En la colección de relatos El anillo encantado (2000), de María Teresa Andruetto y Patricia Melgar, se encuentra un cuento homónimo que presenta a un Carlomagno que se prenda del portador de un anillo mágico sin que esto suponga ningún problema para el monarca, de tal modo que se construye un relato con un personaje bisexual que no hace distinciones entre las personas a la que ama o le gustan; sin embargo en el mismo relato se muestra la homofobia en los personajes masculinos portadores del anillo: Turbado, Aturdido y Asustado, al ponerse el anillo que despierta el amor de Carlomagno hacia su portador, se transforman en el Arzobispo, su asistente y el hombre desconocido, respectivamente.

La editorial Bajo el Arcoíris cuenta con varios títulos con personajes gais. Pecas, el Oso (2012), de Daniel Oropeza y Lita Gómez, narra la historia de un oso que vive en una guardería hasta que un niño llamado Matías decide llevarlo a su casa. Con el paso del tiempo, Pecas va ocupando diferentes posiciones en la habitación de su dueño que le permiten observar cómo este se hace mayor y se convierte en un joven gay. Pecas será guardado en un trastero hasta la llegada de un nuevo niño: el hijo que tiene Matías con otro hombre. De un narrador osezno e interno, se pasa a una historia con una focalización externa en Helbrock, el duende egoísta y la moneda de oro (2012), de Juan Ismael Ruiz y Astrid Rodríguez. Un duende pierde la moneda de oro que, como a todos los de su especie, les conceden al nacer. Los padres le explican que la persona que encuentre la moneda se convertirá en el amor de su vida. Helbrock decide cambiar su actitud vital, decide compartir sus juguetes con sus amigos pues no quiere que su desconocido amor piense de él que es un egoísta. Un día, volviendo a su casa por el camino de las casas humanas encuentra a un niño con su moneda, así que le coge de la mano y lo invita a una fiesta, dando origen a una historia de amor.

En el año 2006, Antonio Orlando Rodríguez denunciaba la escasa presencia de gais, lesbianas, bisexuales o transgénero en la literatura juvenil en América Latina. Recuerda como en En el sur (1988), de Alma Maritano, aparecía el primer homosexual, el tío de una de las adolescentes que protagonizan la novela. Su análisis se centra en Ito (1996), de Luis Cabrera Delgado, en el que destaca la gran calidad literaria de la novela. De acuerdo con su lectura no se puede afirmar que se trate de una novela protagonizada por un niño homosexual, sino de una novela de denuncia sobre la homofobia, la marginación, que pueda sufrir un infante que parezca gay. Ito, ese niño «delicado y fino» debe enfrentarse al rechazo de su tío, de su maestra, incluso de su mejor amigo del colegio, tan solo su abuela parece aceptar su diferencia. Hacia el final de la novela, al acabar la educación primaria y abandonar ese internado que irónicamente se llama La infancia feliz, Ito fantasea con cambiar: actuar y acicalarse como sus compañeros, para ser como los demás, para no ser víctima de la homofobia escolar. Sin embargo, el primer día de la secundaria se encuentra con un director que ya lo conoce por las referencias que le ha dado la homófoba maestra y, por tanto, la vida de Ito no va a poder cambiar como el soñaba. Un mensaje desalentador que construye una sociedad donde reina el rechazo a la diferencia pero que constituye un ejemplo sincero, real de una homofobia social que en el sistema educativo se hace más fuerte (Penna Tosso). Cabe destacar que Ito supone, aún hoy en día, más de quince años después de su publicación, una excepción en el mercado internacional, no sólo de habla hispana, pues pocas novelas dirigidas a lectores a partir de los ocho o diez años, que presenta como protagonista a un niño que se aleja de la conducta heteronormativa convencional.

La novela Un beso de Dick (1992) de Fernando Molano no está considerada como una novela juvenil, y, sin embargo, podría valorarse como una de las mejores novelas de temática gay para adolescentes. Una novela protagonizada por dos jóvenes de dieciséis años que juegan a fútbol, hablan y actúan conforme a su edad: bromean y se pelean, 
se preocupan por los noviazgos, por los embarazos no deseados, por la compra de preservativos o por sus problemas con los adultos, profesores y familias. En su análisis de la literatura gay colombiana, Balderston la define como:

la tierna evocación del descubrimiento del amor homosexual por parte de dos jóvenes en Bogotá, estudiantes del mismo colegio. Un bildungsroman con dimensiones homoeróticas (como tantas otras novelas en la tradición de la novela de aprendizaje), narra la «salida del clóset» de Leonardo y Felipe, sus jóvenes protagonistas, que son puestos a prueba en la escuela, la casa y la calle (1069).

Las dimensiones homoeróticas muestran momentos románticos que insinúan más que describen escenas sexuales. Junto a la recreación de la voz de la adolescencia, la presencia del arte y de la poesía en la novela le aporta un carácter intertextual y metaartístico que enriquecen su lectura. A Felipe le gusta el arte y a Leonardo la literatura, y un día este último explica en clase un poema de Eliseo Diego sobre La virgen de las rocas de $\mathrm{Da}$ Vinci. Narra su experiencia con el poema, alejándose del tratamiento tradicional de la métrica y centrándose en su vivencia sensorial al leerlo. La relación de Leonardo y Felipe no siempre es fácil, se enfrentan a la homofobia escolar y social; sin embargo, el final es un alegato positivo y optimista en el que prevalece una historia de amor con final feliz.

En conclusión, una coincidencia general con respecto a otras latitudes radica en las editoriales: tan sólo aquellas más pequeñas, o especializadas en el tema, se atreven a publicar libros de esta temática. En cuanto a la división temática que establecen Cencerrado y Cedeira (2006), la representación de familias homoparentales coincide en mostrar mayor representación lésbica, de hecho acaba de editarse el primer álbum ilustrado peruano cuyo título evidencia esta preferencia: $; \mathrm{Ca}$ milla tiene dos mamás? Sin embargo, en las historias de personajes no heterosexuales, las publicaciones latinoamericanos muestran una mayor riqueza tanto en el tratamiento temático, no sólo príncipes y princesas, como en la variedad de los personajes destacando no sólo gais y lesbianas, sino incluyendo bisexuales o transgéneros.
Bibliografía

Balderston, Daniel. «Baladas de la loca alegría: literatura queer en Colombia». Revista Iberoamericana, 74: 225, (2008): 1059-1073. Recuperado de:

http://revista-iberoamericana. pitt.edu/ojs/index.php/ Iberoamericana/article/ viewFile/5224/5382. [Fecha de consulta: 27 de septiembre de 2015].

Butler, Judith. El género en disputa, el feminismo y la subversión de la identidad. Barcelona: Paidós, 2007.

Cencerrado, Luis Miguel y Cedeira, Lucía. «La visibilidad de lesbianas y gais en la literatura infantil y

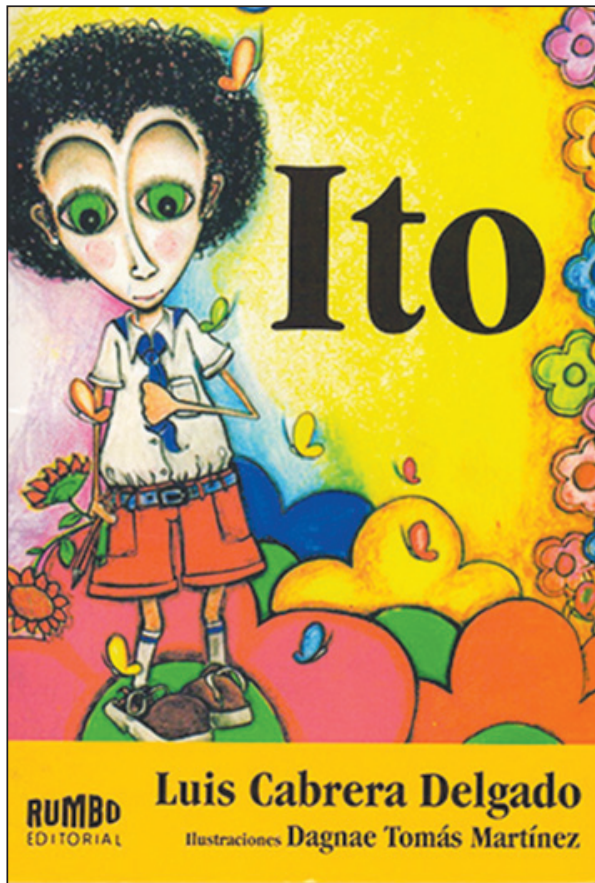

Ito, de Luis Cabrera Delgado. juvenil editada en España». Educación y biblioteca, 152 (2006): 89-102.

Clyde, Laurel A. y Lobban, Marjorie. «A Door Half Open: Young People's Access to Fiction Related to Homosexuality». School Libraries Worldwide, 7:2, (2001): 17-30.

Colomer, Teresa. «Las buenas formas. Tendencias de la literatura infantil y juvenil». Anuario sobre el libro infantil y juvenil 2004. Madrid: SM, 2004: 73-95.

Espinosa, Aurelio M. Cuentos populares recogidos de la tradición oral de España. L. Díaz Viana y S. Asensio Llamas, introducción y notas. Madrid: CSIC, 2009 [1 ${ }^{\text {a }}$ ed. 1946-47].

Foucault, Michel. Historia de la sexualidad 1: La voluntad del saber. Madrid: Siglo XXI, 2003.

Larralde, Gabriela. Los mundos posibles, un estudio acerca de la Literatura LGBTTTI para niñxs. Buenos Aires: Blatt \& Ríos, 2014.

Llorens García, Ramón. «Fábulas, educación literaria y didáctica de los valores: Leo Lionni». E. Luengo Gascón (ed.), Herencia, presente y futuro de la literatura europea: infancia e identidad. Tropelías 23, (2015): 61-72.

Naidóo, Jamie C. Rainbow Family Collection: Selecting and Using Children's Books with Lesbian, Gay, Bisexual, Transgender, and Queer Content. Santa Barbara, CA: Libraries Unlimited, 2012.
La representación de la diversidad afectivo-sexual en la literatura infantil y juvenil de América Latina GUILLERMO SOLER QUILES 
Penna Tosso, Melani. Formación del profesorado en la atención a la diversidad afectivo-sexual. [Tesis Doctoral]. 2012. Recuperado de: http://eprints.ucm.es/16718/1/ T34011.pdf [Fecha de consulta: 27 de septiembre de 2015].

Rodríguez, Antonio Orlando. «Ito: el 'raro' en la literatura infantil cubana». Revista Encuentro (2006): 41/42. Recuperado de: http://www.cuatrogatos.org/docs/articulos/articulos_184.pdf [Fecha de consulta: 27 de septiembre de 2015].
Ruiz Elvira, Antonio. Mitología clásica. Madrid: Gredos, 1995.

Yellati, Néstor. "Yo nena, yo princesa (o la niña con pene). Bordes de lo femenino», Virtualia, revista digital de la EOL (2015). Recuperado de: http://virtualia.eol.org. ar/030/Bordes-de-lo-femenino/PDF/Yonena-yo-princesa.pdf [Fecha de consulta: 27 de septiembre de 2015].

Fecha de recepción: 01/07/2015

Fecha de aceptación: 01/10/2015 